\title{
Changes in Nutritional Status of 5-6 year old Children in Podgorica between 2013 and 2020
}

\author{
Milica Vucerakovic ${ }^{1}$, Milena Mitrovic ${ }^{2}$ \\ ${ }^{1}$ University of Montenegro, Faculty for Teacher Education, Niksic, Montenegro, ${ }^{2}$ University of Montenegro, Faculty for Sport and Physical Education, \\ Niksic, Montenegro
}

\section{Abstract}

The aim of this research was to analyze the level of nutrition of students enrolled in primary school in 2013 and students enrolled in primary school in 2020. The research includes data on the height and weight of children from the obligatory systematic examinations. These systematic examinations included a sample of 82 children. We divided them into four subsamples. The first subsample consists of 19 boys enrolled in school in $2013(n=19)$, and the second 18 girls enrolled in the same year $(n=18)$. The third subsample consists of 24 boys enrolled in 2020 $(n=24)$, and the fourth 21 girls enrolled in $2020(n=21)$. The measurement was performed by health workers at the PHI Health Center "Nova Varos" in Podgorica. Body mass and body height are determinated, and that was the basis for calculation of the body mass index (BMI). For all variables, were calculated the values of the measures of central and dispersion tendency. Differences in body parameters for assessing nutrition between children were determined using the t-test for small and independent samples and the Hi square test. The percentage of obese boys enrolled in 2013 was $28 \%$, obese girls $0 \%$, the percentage of obese boys enrolled in 2020 was $21 \%$, and obese girls was 19\%. There are statistically significant differences between boys measured in 2013 and 2020, in favor of boys measured in 2020. There are also statistically significant differences between girls measured in 2013 and 2020 (obese girls were measured in 2020). When it comes to comparing genders by age, there are statistically significant differences in favor of girls measured in 2013 and girls measured in 2020. It can be concluded that obesity is on the rise, given the fact that more obese children are enrolled in school in 2020.
\end{abstract}

Keywords: Children, Obesity, Height, Weight, BMI

\section{Uvod}

Još od svog nastanka čovjek je imao potrebu da bude fizički aktivan (kreće se, traži hranu, uređuje svoju okolinu i sl.). Međutim, industrijalizacija i razvoj tehnike i tehnologije dovele su do sve manje potrebe za ljudskim radom, pa time i stvarne potrebe za fizičkom aktivnošću čovjeka. I ishrana čovjeka se tokom evolucije značajno mijenjala. Nekad su ljudi išli u potragu za hranom i za jelo su imali samo to što nađu ili ulove. Kao posljedica toga, logične su i promjene u stepenu uhranjenosti kod ljudi. Danas nam je hrana značajno dostupnija. Ta dostupnost čovjeku pruža mogućnost da jede kad hoće i koliko hoće. Takođe, gotovo sva današnja hrana je industrijski prerađena (sadrži mnogo dodatog šećera, pojačivače ukusa, konzervanse i sl.), što je čini kalorični-

\section{jom i nezdravijom.}

Stepen uhranjenosti je parametar koji služi za kvalifikaciju odstupanja stanja uhranjenosti od normale, a ona se može kretati od ekstremne pothranjenosti do patološke gojaznosti. Neuhranjenost, prekomjerna uhranjenost i gojaznost štetno utiču na metabolizam i, globalno posmatrano, predstavljaju značajne medicinske i socio-ekonomske probleme (Masanovic, Bavcevic, \& Prskalo, 2019). Ipak, u posljednje vrijeme mnogo više zabrinjava prekomjerna uhranjenost ili gojaznost, koja nastaje upravo kao posljedica nedostatka fizičke aktivnosti i nezdrave ishrane. Svjetska zdravstvena organizacija gojaznost definiše kao abnormalno nakupljanje masti u tijelu koje predstavlja veliki rizik za zdravlje. To je hronično oboljenje koje karakteriše povećanje masne ma-

Correspondence:

\section{Montenegro M.Vucerakovic}

Sport University of Montenegro, Faculty for Teacher Education, Danila Bojovica bb, 81400, Niksic, Montenegro E-Mail: milicavucerakovic@gmail.com 
se tijela, u mjeri koja dovodi do narušavanja zdravlja i razvoja niza komplikacija (Vukušić, Filipović i Milićev, 2015; Mitrovic \& Dragutinovic, 2020). Gojaznost i fizička neaktivnost glavni su faktori rizika za brojne hronične bolesti, uključujući dijabetes tipa 2, osteoporozu, kardiovaskularne bolesti i rak (Ćirković, 2012.). Prema podacima Svjetske zdravstvene organizacije, 1.9 milijardi odraslih ljudi (18 godina i stariji) imalo je problema sa prekomjernom tjelesnom masom, dok je 462 miliona ljudi bilo neuhranjeno (WHO, 2016). Što se tiče djece, 14.3 miliona ima malu tjelesnu masu za svoju visinu (WHO, 2016). Čak 45\% smrti djece do 5 godina je povezano sa neuhranjenošću (WHO, 2017). Neuhranjenost je veliki problem u zemljama sa niskim životnim dohotkom, posebno u Africi (izuzev par zemalja u njenom sjevernom i južnom regionu). Nekada smatrani problemom samo u zemljama sa visokim životnim standardom, prekomjerna uhranjenost i gojaznost sada dramatično bilježe porast u zemljama sa niskim i srednjim životnim standardom, posebno u urbanim sredinama (NCD Risk Factor Collaboration, 2014; Djoric \& Vukicevic, 2020). Međutim, u novijem istraživanju koje je za prestižni svjetski časopis „Nature" sproveo tim naučnika, navodi se da je stepen gojaznosti veći u ruralnim nego u urbanim područjima (NCD Risk Factor Collaboration, 2019). Trend rasta gojaznosti je zabrinjavajući, iz razloga što gojaznost negativno utiče na zdravlje i skraćuje životni vijek (Mitrović \& Dragutinović, 2020). Dosta istraživanja upućuje i na porast gojaznosti u Crnoj Gori (Vrevic 2019; Banjevic, 2019; Masanovic et al., 2020; Vasiljevic, 2020). Stoga, osnovni cilj ovog rada je utvrditi nivoe uhranjenosti djece prvog razreda generacije 2013. i 2020., kao i eventualne razlike među njima, kako bi se sagledao trend kretanja gojaznosti kod djece ovog uzrasta u Podgorici.

\section{Metod}

Mjerenja pomoću kojih su dobijeni podaci o visini i masi djece sprovedena su od strane zdravstvenih radnika u JZU Dom zdravlja "Nova Varoš". Budući da se radilo o sistematskom pregledu, roditelji i njihova djeca su upućeni u svrhu mjerenja. Sistematskim pregledom prikupljeni su podaci o postojanju ili nepostojanju deformiteta kičmenog stuba, ličnoj higijeni djeteta kao i neki podaci koji ukazuju na opšte zdravstveno stanje djeteta, a za ovo istraživanje uzeti su podaci o tjelesnoj visini, tjelesnoj masi i uzrastu ispitanika. Na osnovu podataka o uzrastu, tjelesnoj visini i tjelesnoj masi djece, izračunat je pomoću standardne formule (Williamson et al., 2020). Ispitanici su mjereni u medicinskoj ambulanti, odjeveni u donji veš i bosi. Za ovo mjerenje korišćena je Medicinska vaga sa pomičnim tegovima i stadiometrom, a dobijeni rezultati su evidantirani u kartonima svakog učenika ponaosob kao i na zajedničkom dokumentu - evidenciji o radu. Ovim istraživanjem obuhvaćen je uzorak od 82 djeteta, od kojih je 42 mjereno u periodu april-maj 2013. godine, a $40 \mathrm{u}$ periodu aprilmaj 2020. godine. Uzorak je podijeljen na četiri subuzorka. Prvi subuzorak čine 24 dječaka upisana u školu 2013. godine $(n=24)$ prosječnog uzrasta 5 godina i 8 mjeseci, a drugi 18 djevojčica upisanih iste godine $(n=18)$ prosječnog uzrasta 5 godina i 6 mjeseci, treći subuzorak sačinjava 19 dječaka upisanih u školu 2020. godine $(\mathrm{n}=19)$ prosječnog uzrasta 5 godina i 9 mjeseci, a četvrti 21 djevojčica upisana 2020. godine $(n=21)$ prosječnog uzrasta 5 godina i 8 mjeseci. Podaci dobijeni u istraživanju obrađeni su pomoću programa specijalizovanog za statističku obradu podataka - IBM SPSS Statistics 20. Korišćeni su postupci deskriptivne statističke procedure - aritmetička sredina i standardna devijacija. Analiza stepena uhranjenosti urađena je na osnovu Indeksa tjelesne mase (BMI), klasifikujući ispitanike u jednu od sljedećih kategorija: preko 95 percentila - gojazni, od 85 do 95 percentila - prekomjerno uhranjeni, od 5 do 85 percentila - normalno uhranjeni i od 0 do 5 percentila - pothranjeni. Od komparativne statistike, korišćen je Hi kvadrat test sa statističkom značajnošću od 0,01 , da bi se uporedile razlike u nivoima uhranjenosti između dječaka mjerenih 2013. i 2020. godine i između djevojčica mjerenih 2013. i 2020. godine.

\section{Rezultati}

U Tabeli 1 prikazani su osnovni deskriptivni parameri dječaka i djevojčica mjerenih 2013. i 2020. godine: tjelesna visina, tjelesna masa, minimalni rezultat, maksimalni rezultat, aritmetička sredina, standardna devijacija, mjera asimetričnosti Skjunis i mjera zakrivljenosti Kurtozis.

Tabela 1. Deskriptivna statistika dječaka i djevojčica upisanih 2013. i 2020. godine

\begin{tabular}{lccccccc}
\hline Subuzorak & Varijable & Min & Max & Mean & SD & Skew. & Kurt. \\
\hline \multirow{2}{*}{ Dječaci mjereni 2013. } & Tjelesna visina & 105.0 & 128.0 & 117.56 & 6.21 & -.088 & -.241 \\
& Tjelesna masa & 17.0 & 34.0 & 23.88 & 4.81 & .343 & -.974 \\
Dječaci mjereni 2020. & Tjelesna visina & 111.0 & 127.0 & 118.42 & 4.18 & .254 & .053 \\
& Tjelesna masa & 18.0 & 39.0 & 24.68 & 5.59 & 1.039 & 1.027 \\
Djevojčice mjerene 2013. & Tjelesna visina & 105.0 & 126.0 & 116.09 & 6.22 & -298 & -.920 \\
& Tjelesna masa & 26.0 & 28.0 & 21.53 & 3.20 & .228 & -.376 \\
Djevojčice mjerene 2020. & Tjelesna visina & 106.0 & 138.0 & 120.38 & 6.96 & .558 & 1.290 \\
& Tjelesna masa & 18.0 & 38.0 & 24.57 & 5.11 & 1.095 & 1.135 \\
\hline
\end{tabular}

Legenda: Min- minimalna vrijednost, Max- maksimalna vrijednost, Mean- aritmetička sredina, SD- standardna devijacija, Skew.- skjunis, Kurt.- kurtozis

Prosječne vrijednosti tjelesne mase dječaka i djevojčica mjerenih 2020. godine veće su nego kod onih mjerenih 2013. godine. Prosječna tjelesna masa povećala se za nešto manje od $1 \mathrm{~kg}$ kod dječaka, a za nešto više od $3 \mathrm{~kg}$ kod djevojčica. Trend povećanja prosječne tjelesne mase, prati i povećanje prosječne tjelesne visine. Prosječna tjelesna visina dječaka mjerenih 2020. veća je za skoro $1 \mathrm{~cm}$ od prosječne tjelesne visine dječaka mjerenih 2013 godine, dok je kod djevojčica mjerenih 2020. veća za čak preko 4 centimetra nego kod djevojčica mjerenih 2013. godine. Ako uporedimo srednje vrijednosti tjelesne mase dječaka i djevojčica za obije godine, vidjećemo da su nešto veće kod dječaka. Ono što iznenađuje jeste podatak da djevojčice mjerene 2020. imaju veću maksimalnu i prosječnu tjelesnu visinu od dječaka mjerenih iste godine, dok 2013. to nije bio slučaj.

U Tabeli 2 prikazane su frekvencije i kumulativne frekvencije za sva četiri subuzorka.

Kada su u pitanju dječaci mjereni 2013. godine, 2 (11\%) su neuhranjena, 8 (42\%) ima normalnu tjelesnu masu, 5 (21\%) prekomjernu tjelesnu masu i 4 (21\%) su gojazna. Kod dječaka mjerenih 2020. godine, neuhranjenih nije bilo (0\%), normalnu tjelesnu 
Tabela 2. Frekvencije i kumulativne frekvencije nivoa uhranjenosti dječaka i djevojčica mjerenih 2013. i 2020. godine

\begin{tabular}{lcccccccc}
\hline \multirow{2}{*}{ Kategorije } & \multicolumn{2}{c}{ Dječaci - 2013. } & \multicolumn{2}{c}{ Dječaci - 2020. } & \multicolumn{2}{c}{ Djevojčice - 2013. } & \multicolumn{2}{c}{ Djevojčice - 2020. } \\
\cline { 2 - 9 } & $\mathbf{N}$ & \% & $\mathbf{N}$ & $\mathbf{\%}$ & $\mathbf{N}$ & \% & $\mathbf{N}$ & \% \\
\hline Neuhranjenost & 2 & 11 & 0 & 0 & 0 & 0 & 1 & 5 \\
Normalna masa & 8 & 42 & 11 & 44 & 14 & 82 & 13 & 62 \\
Prekomjerna masa & 5 & 26 & 7 & 28 & 3 & 18 & 3 & 14 \\
Gojaznost & 4 & 21 & 7 & 28 & 0 & 0 & 4 & 19 \\
Ukupno & 19 & 100 & 25 & 100 & 17 & 100 & 21 & 100 \\
\hline
\end{tabular}

Legenda: $\mathrm{N}$ - broj; \% - procenat

masu imalo je 11 (44\%) dječaka, dok je prekomjerno uhranjenih i gojaznih bilo po 7 (28\%). Kod djevojčica mjerenih 2013. godine nema neuhranjenih i gojaznih (0\%), njih 14 (82\%) ima normalnu tjelesnu masu, dok su 3 (18\%) prekomjerno uhranjene. Što se tiče djevojčica mjerenih 2020. godine, jedna (5\%) je neuhranjena, 13 (62\%) ima normalnu tjelesnu masu, 3 (14\%) su prekomjerno uhranjene, a 4 (19\%) gojazne.
$\mathrm{U}$ Tabeli 3 prikazane su razlike u kumulativnim frekvencijama kojima su izraženi nivoi uhranjenosti između ispitanika oba pola mjerenih u 2013. i 2020. godini.

Iz Tabele 3 možemo zaključiti da se procentualna zastupljenost neuhranjenih, uhranjenih, prekomjerno uhranjenih i gojaznih razlikuje po polovima i godinama. I kod dječaka i kod djevojčica, gojazniji su oni koji su mjereni 2020. nego oni mjereni 2013. godine.

Tabela 3. Hi kvadrat test za utvrđivanje razlika u nivoima uhranjenosti između dječaka mjerenih 2013. i 2020. godine i između djevojčica mjerenih 2013. i 2020. godine

\begin{tabular}{lcl}
\hline Pol & Df & Sig. \\
\hline Dječaci (2013-2020) & 1 & .000 \\
Djevojčice (2013-2020) & 1 & .000 \\
\hline
\end{tabular}

Legenda: df - stepeni slobode, Sig. - nivo značajnosti

\section{Diskusija}

S obzirom da se problemi sa prekomjernom uhranjenošću i gojaznošću povećavaju iz godine u godinu, kako kod nas tako i širom svijeta, cilj ovog istraživanja bio je da se utvrdi stepen uhranjenosti učenika i učenica prvog razreda upisanih u školu 2013. i 2020. godine. Procenat gojaznih dječaka upisanih 2013. godine iznosi $28 \%$, a procenat gojaznih dječaka upisanih 2020. godine iznosi $21 \%$. Procenat gojaznih djevojčica upisanih 2020. godine iznosi $0 \%$, a gojaznih djevojčica mjerenih 2020 . godine $19 \%$. Može se zaključiti da je više gojazne djece upisano 2020. godine, što je i očekivano, s obzirom da je globalna studija, koja je obuhvatila više od 130 miliona i djece, pokazala da se broj gojazne djece i adolescenata povećao 10 puta za 40 godina, kao i da svakodnevno raste (NCD Risk Colaboration, 2017).

Kada je riječ o tjelesnoj visini učenika prvog razreda, nije karakteristično da su djevojčice visočije od dječaka. Prema većini istraživanja, bez obzira da li su starijeg ili novijeg datuma, dječaci su nešto visočiji (Bala, 1981; Pavlović, 1985; Gajević, 2009; Doder, 2010). Međutim, postoje istraživanja koja pokazuju suprotno - veću prosječnu tjelesnu visinu djevojčica. Jedno od starijih istraživanja sprovedenih nad učenicima upisanim u prvi razred pokazuje da su vrijednosti prosječne tjelesne visine djevojčica bile veće za oko $3 \mathrm{~cm}$ nego kod dječaka istog uzrasta (Ahmetović i sar., 1990). Trideset godina kasnije, Pelemiš i sar. (2020) su upoređujući nivoe uhranjenosti dječaka i djevojčica starijeg predškolskog uzrasta došli do statistički značajne razlike u korist djevojčica, što su objasnili sve ranijim polnim sazrijevanjem djevojčica, tj. ulaskom u pubertet, a opšte poznato je da se u tom periodu kod djevojčica povećava sakupljanje masnog tkiva, što je pokazano i ovim istraživanjem.

Ovo istraživanje takođe ukazuje da je danas, u našoj zemlji, gojaznost značajno veči problem od pothranjenosti. Međutim, osnovni nedostatak ovog rada je mali uzorak ispitanika, pa je potrebno nastaviti sa daljim istraživanjima, kako bi se dobila što potpunija i preciznija slika o stanju uhranjenosti djece u Crnoj Gori i sproveli adekvatni postupci za njeno sprječavanje i širenje. Vrlo je važno da profesori razredne nastave ili fizičkog vaspitanja preventivno reaguju i redovno prate i provjeravaju stepen uhranjenosti djece. Ako primijete da ima gojaznih, taj problem će rješavati adekvatnim planiranjem i programiranjem rada u nastavi fizičkog vaspitanja, a bilo bi dobro i obavijestiti roditelje, kako bi se povelo računa o ishrani djeteta i eventualno ih upututi na neke dodatne vidove fizičkih aktivnosti (školice sporta, sportski klubovi, sekcije i sl.). Samo uz takav, pravilan pristup, nesmetanu i kvalitetnu saradnju i sa djetetom i roditeljima i nesebično pružanje podrške, može se doći do pozitivnih promjena u ishrani, fizičkoj aktivnosti, a vremenom i u izgledu i zdravlju djeteta.

\section{Acknowledgments}

There are no acknowledgements.

\section{Conflict of Interest}

The authors declare that there is no conflict of interest.

Received: 13 July 2020 | Accepted: 15 November 2020 | Published: 18 January 2021

\section{References}

Ahmetović, Z., Pavlović, Đ. i Popmihajlov, D. (1990). Fizički razvoj i fizičke sposobnosti stanovništva SAP Vojvodine. Novi Sad: Zavod za fizičku kulturu Vojvodine.

Bala, G. (1981). Struktura i razvoj morfoloških i motoričkih dimenzija dece SAP Vojvodine. Novi Sad: Fakultet fizičke kulture.

Bala, G. (2007). Morfološke karakteristike predškolske dece. Novi Sad: Fakultet sporta i fizičkog vaspitanja.

Banjevic, B. (2019). Differences in some morphological characteristics and body mass index in children of younger school age with reference to their gender. Journal of Anthropology of Sport and Physical Education, $3(3), 37-41$.

Ćirković, V. (2012). Uticaj fizičke aktivnosti na gojaznost kod dece. Neobjavljeni diplomski rad, Beograd: Fakultet sporta i fizičkog vaspitanja.

Djoric, N., \& Vukicevic, V. (2020). Nutritional Status of Young School Children in a Rural Environment in Srem District. Journal of Anthropology of Sport and Physical Education, 4(2), 19-21.

Doder, D. (2010). Fizička razvijenost i fizičke sposobnosti dece osnovnoškolskog uzrasta. Novi Sad: Pokrajinski zavod za sport.

Gajević, A. (2010). Fizička razvijenostifizičkesposobnostideceosnovnoškolskog 
uzrasta. Beograd: Republički zavod za sport.

Kavarić, N. Gojaznost kao faktor rizika od nastanka kardiovaskularnih poremećaja u dece školskog uzrasta. Neobjavljena doktorska disertacija Podgorica: Medicinski fakultet.

Masanovic, B., Bavcevic, T., \& Prskalo, I. (2019). Comparative Study of Anthropometric Measurement and Body Composition between Junior Handball and Basketball Players from the Serbian National League, Pedagogics, psychology, medical-biological problems of physical training and sports, 23(2), 90-95.

Masanovic, B., Martinovic, S., Zoric, G., Bacovic, D., Mitrovic, M., \& Vukotic, M. (2020). Trends in Body Height, Body Weight, and Body Mass Index from 1979 to 1987: An Analysis of the Young Male Population from the Municipality of Cetinje, Journal of Antropology of Sport and Physycal Education, 4(2), 3-7.

Mitrovic, M., \& Dragutinovic, K. (2020). Comparative Analysis of Anthropometric Parameters as Obesity Indicators for 7-8 Years-old Children of Different Resident Status, Journal of Antropology of Sport and Physical Education, 4(1), 43-46.

NCD Risk Factor Collaboration (2014). Global, regional, and national prevalence of overweight and obesity in children and adults during 1980-2013: A systematic analysis for the Global Burden of Disease Study 2013. The Lancet, 384 (9945) 766-781.

NCD Risk Factor Collaboration (2017). Worldwide trends in body-mass index, underweight, overweight, and obesity from 1975 to 2016: pooled analysis of 2416 population-based measurement studies in 128.9 million children, adolescents, and adults, The Lancet, 390 (10113)
2627-264(2).

NCD Risk Factor Collaboration (2019). Rising rural body-mass index is the main driver of the global obesity epidemic in adults, Nature, 569(2019) 260-264.

Pavlović, Đ. (1985). Fizička razvijenost i fizičke sposobnosti stanovnika SAP Vojvodine. Novi Sad: Zavod za fizičku kulturu Vojvodine.

Pelemiš, V., Pavlović, S., Nikolić, I.,\& Ujsasi, D. (2020). Body Mass Index and Motor Status of Preschool Children, Sports Science and Health, 10(1), $17-25$.

Stupar, D., Popović, B., \& Vujović, P. (2012).Stanje uhranjenosti predškolske dece Novog Sada, Journal of the Anthropological Society of Serbia, 49(5), 51-55.

Vasiljević, I. (2020). Antropometrijski parametri kao indikatori gojaznosti kod adolescenata u Crnoj Gori. Neobjavljena doktorska disertacija, Nikšić: Fakultet za sport i fizičko vaspitanje.

Vrević, E. (2019). Stepen uhranjenosti učenika drugog i trećeg razreda osnovnih škola u Herceg Novom. Neobjavljeni diplomski rad, Nikšić: Fakultet za sport i fizičko vaspitanje.

Williamson, K., Nimegeer, A., \& Lean, M. (2020). Rising prevalence of $B M l \geq 40 \mathrm{~kg} / \mathrm{m}^{2}$ : A high demand epidemic needing better documentation, Obesity reviews, 21(4), 1-12.

World Health Organization. (2017). Guideline: assessing and managing children at primary health-care facilities to prevent overweight and obesity in the context of the double burden of malnutrition. Updates for the integrated management of childhood illness (IMCI). Geneva: World Health Organization. 